\title{
COMPARISON OF PREVALENCE AND RESECTION RATES IN PATIENTS WITH ESOPHAGEAL SQUAMOUS CELL CARCINOMA AND ADENOCARCINOMA
}

Richard F. Heitmiller, MD

Rohit R. Sharma, BA
Since 1987 we have observed a predominance of adenocarcinoma in patients undergoing esophagectomy because of carcinoma at our institution. To discover whether this observation represented an actual change in the prevalence of adenocarcinoma, the Johns Hopkins Hospital pathology records were reviewed for the years 1959 to 1994 . Overall, esophageal squamous cell carcinoma was the most common histologic type with 817 cases identified versus 284 cases of adenocarcinoma. The number of patients with squamous cell carcinoma rose slowly from 1959 to 1992 but since 1992 has decreased. Whereas adenocarcinoma was uncommon before 1978, its frequency has since increased markedly, exceeding that of squamous cell carcinoma in 1994. The number of patients with adenocarcinoma who underwent surgical resection has equaled or exceeded the number of those treated nonoperatively for all recorded years. Therefore the predominance of adenocarcinoma in patients undergoing esophageal resection for carcinoma appears to result from two factors: an overall increase in the prevalence of adenocarcinoma since 1978 and an increased likelihood of resection for patients with these tumors. (J Thorac Cardiovasc Surg 1996;112:130-6)
$S^{\text {in }}$ nce 1987 we have observed a predominance of adenocarcinoma in patients undergoing esophageal resection because of carcinoma at our institution. To discover whether this observation represented an actual change in the prevalence of esophageal adenocarcinoma or whether it was a result of surgical selection bias, the Johns Hopkins Hospital surgical pathology records were reviewed over a study period that spanned four decades (1959 through 1994) to determine both the yearly prevalence and number of surgical resections in patients with esophageal squamous cell carcinoma (SCCA) and adenocarcinoma.

\section{Patients and methods}

The surgical pathology records were reviewed to identify all patients in whom the pathologic diagnosis of primary

From the Department of Surgery, Division of General Thoracic Surgery, The Johns Hopkins Medical Institutions, Baltimore, Md.

Supported by the Evelyn Glick Fund for Thoracic Surgery.

Received for publication May 9, 1995; accepted for publication August 30, 1995.

Address for reprints: Richard Heitmiller, MD, The Johns Hopkins Hospital, 600 N. Wolfe St., Osler 624, Baltimore, MD 21287-5674.

Copyright $(1) 1996$ by Mosby-Year Book, Inc.

$0022-5223 / 96 \$ 5.00+0 \quad \mathbf{1 2 / 1 / 6 9 0 6 2}$
SCCA or adenocarcinoma was made at the Johns Hopkins Hospital between 1959 and 1994. Patients with SCCA or adenocarcinoma that secondarily invaded the esophagus from a nonesophageal primary tumor and patients in whom the esophagus was involved with metastatic disease were excluded. Primary gastric adenocarcinoma was excluded. Eleven patients had undifferentiated esophageal carcinoma that was not classified as SCCA or adenocarcinoma and these were also excluded from this study.

From the pathology report, age, sex, and whether the specimen was from a biopsy procedure or resection were recorded for each patient. Patient race was recorded from the pathology records through 1984, when this information was dropped from the pathology database. From 1985 to 1992 , patient race was obtained from the medical records. From 1992 to 1994, patient race was not recorded. Each patient was counted only once.

A patient in whom the tumor was diagnosed by biopsy and in whom no surgical resection was done was recorded in the biopsy (nonoperative) group. Multiple synchronous or metachronous biopsies of the same tumor were counted as one event. Alternatively, patients in whom the tumor was resected, or sampled for biopsy and resected, were recorded under a single event each in the resection (surgical therapy) group. Patients in whom the diagnosis of SCCA or adenocarcinoma was made or reviewed at our institution and who received neoadjuvant chemoradiation therapy followed by esophageal resection and in whom no residual SCCA or adenocarcinoma was identified in the resection specimen (complete histologic response) were included and recorded in the resection group under the cell type determined by pretherapy biopsy. The results were tabulated by year. 


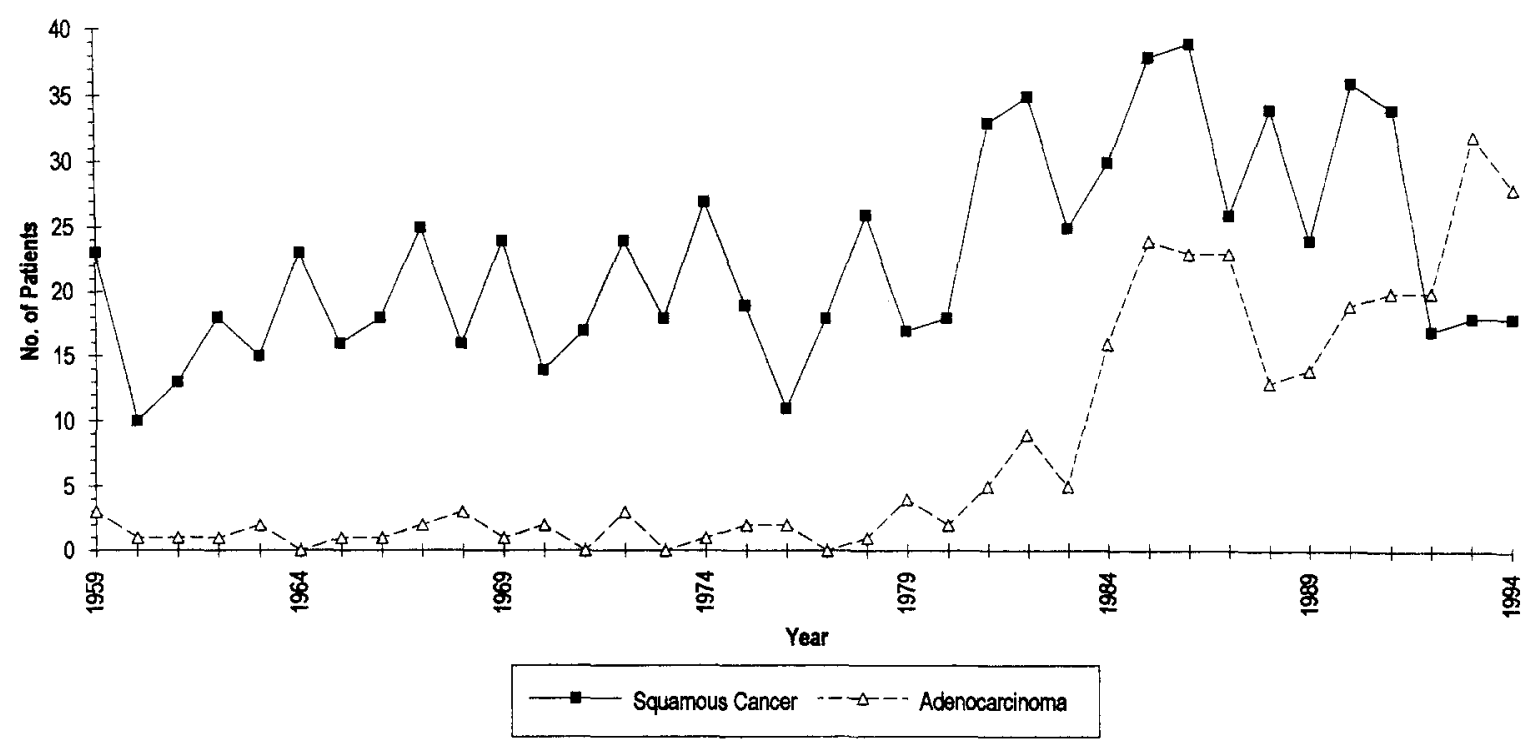

Fig. 1. Total number of patients with esophageal SCCA and adenocarcinoma by year.

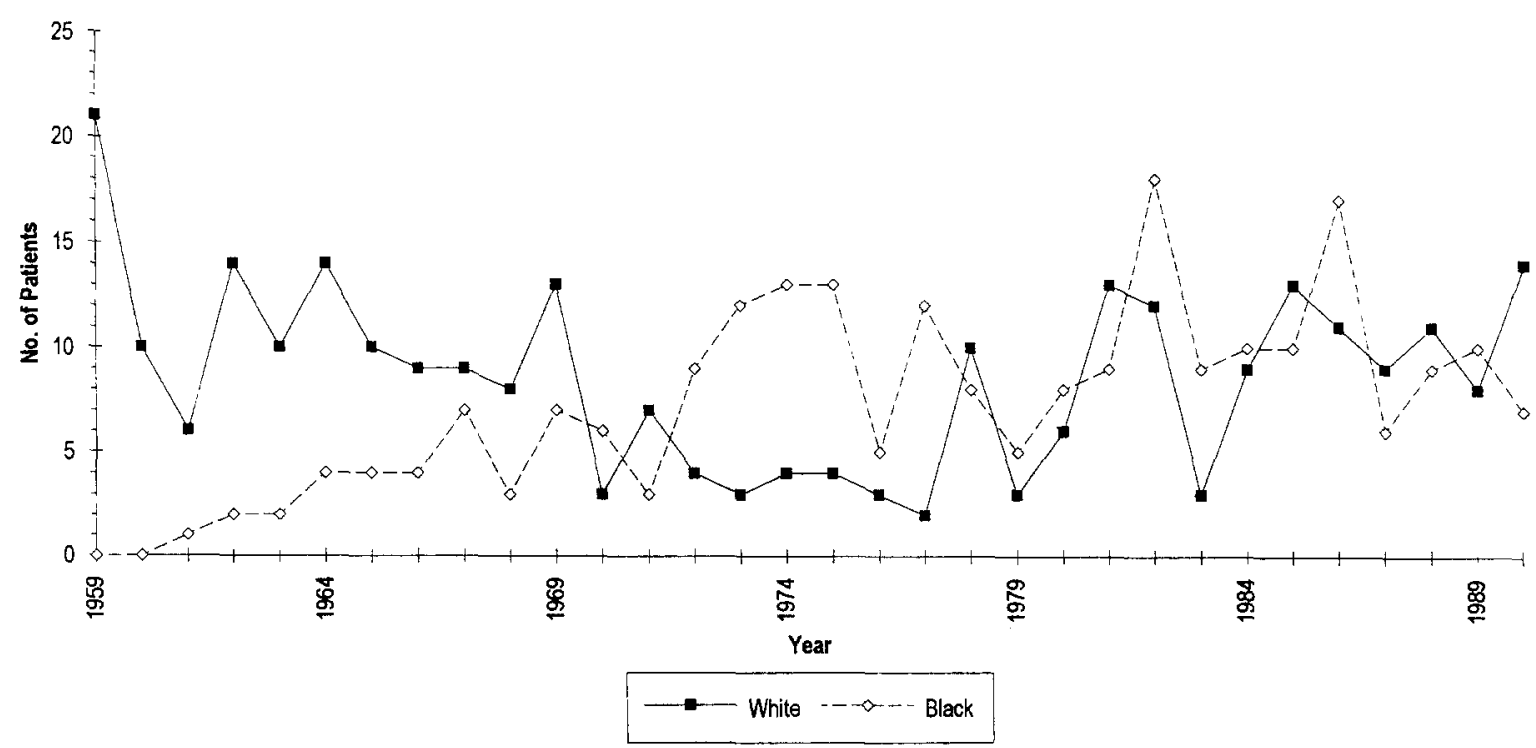

Fig. 2. Yearly number of white and black male patients with esophageal SCCA.

\section{Results}

Between 1959 and 1994, 1101 cases of SCCA or adenocarcinoma were noted in the pathology records at the Johns Hopkins Hospital. There were 817 patients with SCCA and 284 patients with adenocarcinoma. The number of patients with a diagnosis of SCCA and adenocarcinoma per year is shown in Fig. 1. Overall, SCCA was the most common cell type. The number of patients with SCCA slowly increased from 1959 to 1992 and then decreased from 1992 to 1994 . Adenocarcinoma was uncommon before 1978. Beginning in 1978, the number of patients with adenocarcinoma increased sharply and in 1994 for the first time since 1959 the number of patients with adenocarcinoma exceeded that of patients with SCCA.

The yearly prevalence of SCCA in white and black male patients is shown in Fig. 2. Between the years 1959 and 1970, SCCA was more common in white male patients. This trend was reversed for the next 


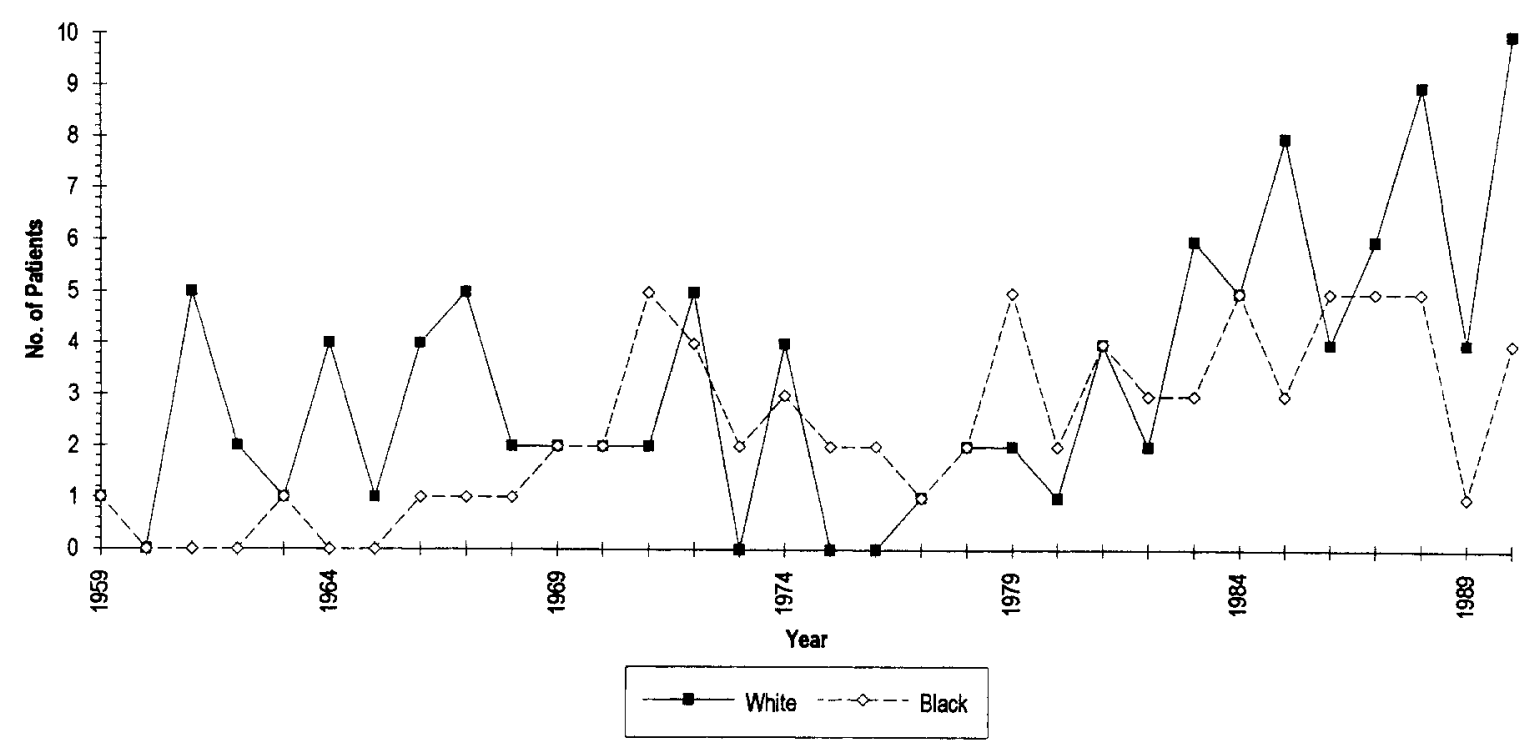

Fig. 3. Yearly number of white and black female patients with esophageal SCCA.

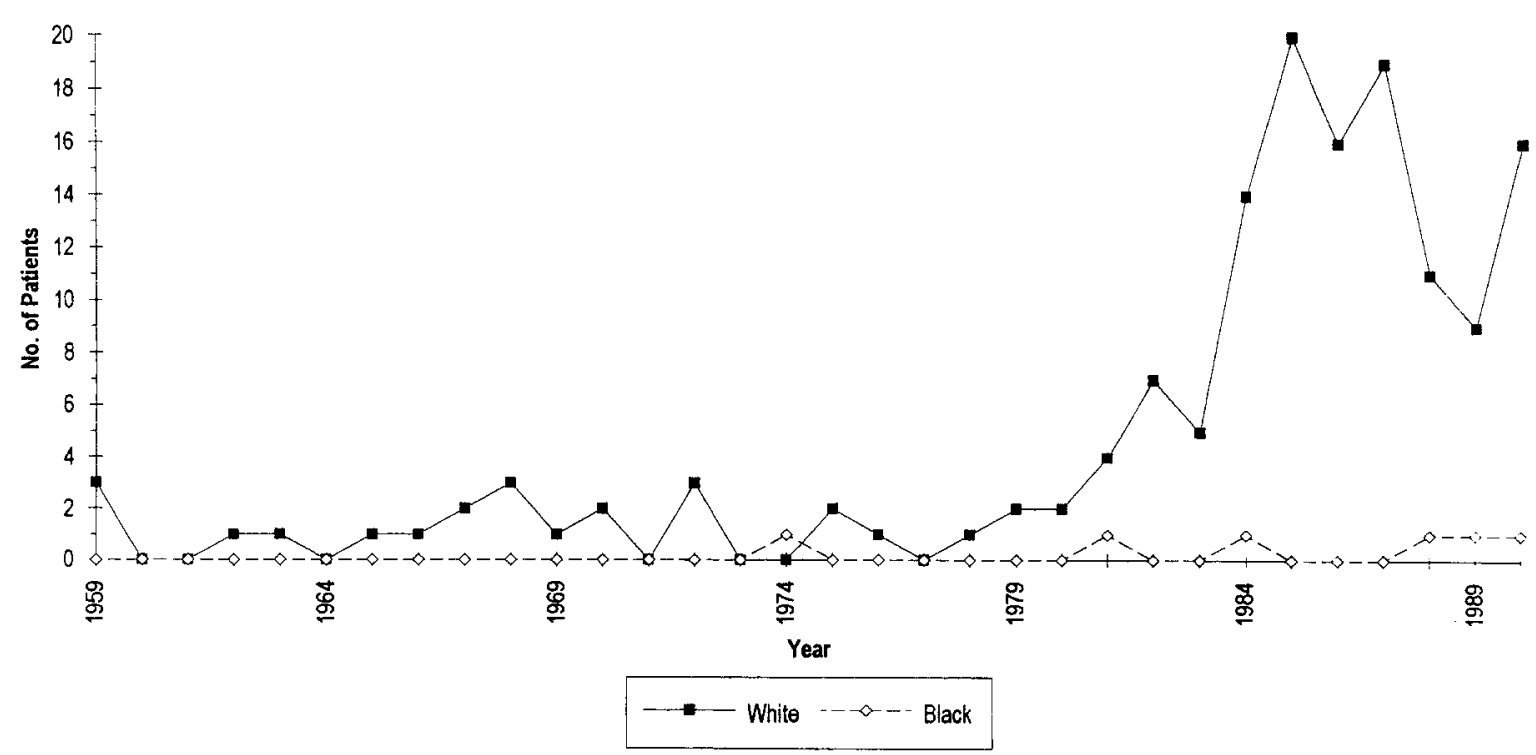

Fig. 4. Yearly number of white and black male patients with esophageal adenocarcinoma.

eight years (1970 through 1978) and subsequently, from 1978 to the present, the frequency of SCCA in white and black male patients was equal. The yearly number of white and black female patients with SCCA is shown in Fig. 3. During the first decade (1959 to 1969), SCCA was more common in white female patients. Between 1970 and 1982 the number of black female patients with SCCA equaled or exceeded that of white female patients, and from 1983 to the present this trend was reversed with a sharp increase in the number of white women with SCCA.

The yearly prevalence of adenocarcinoma in white and black male patients is shown in Fig. 4. The number of white male patients with adenocarcinoma has equaled or exceeded that of black male patients in all years since 1959 except in 1974 (1 black man, 0 white men). Beginning in 1978 and continuing to the present, the number of white male patients with adenocarcinoma has risen sharply without any cor- 


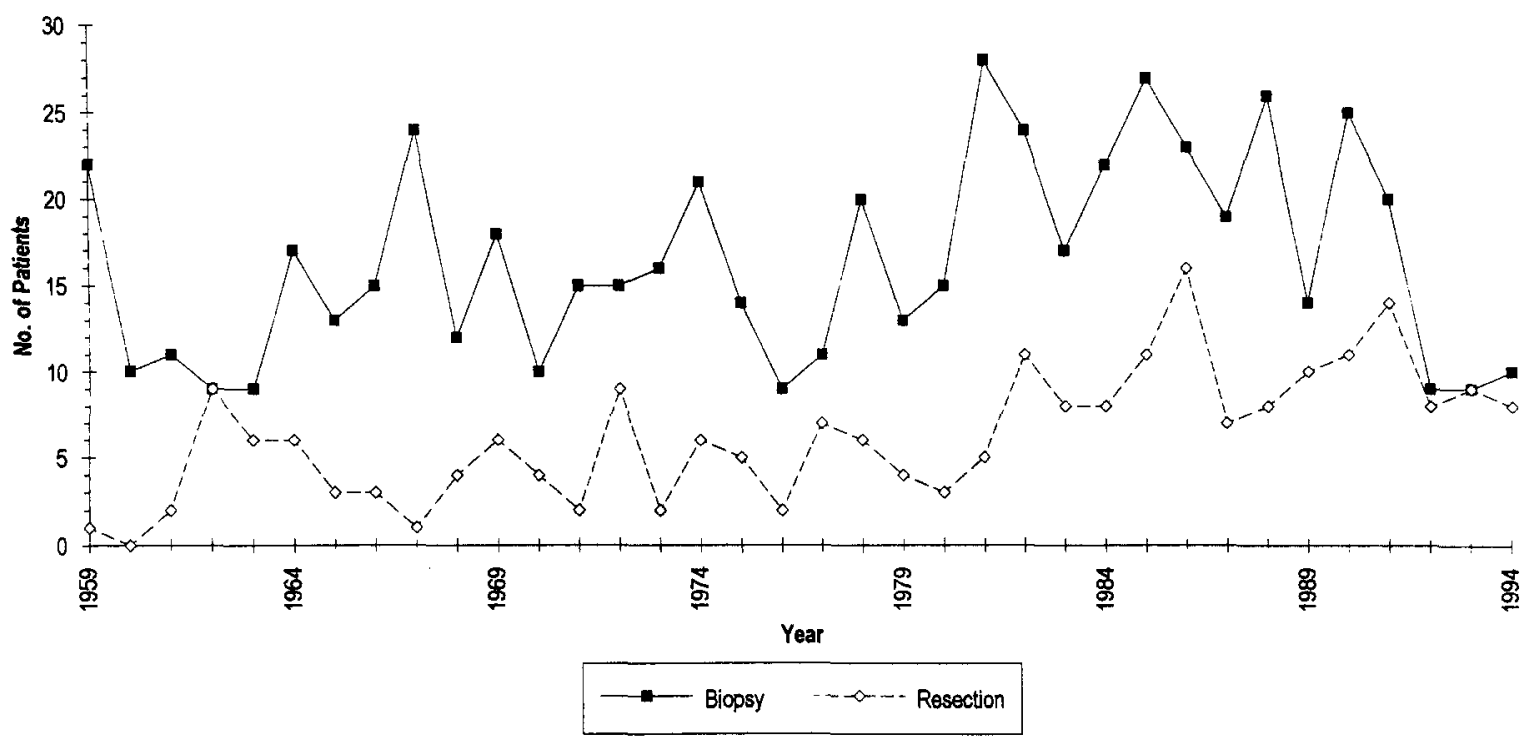

Fig. 5. Yearly number of total patients with SCCA treated with and without (biopsy) surgical resection.

responding change in the number of black male patients observed. Adenocarcinoma in women was uncommon. The frequency of adenocarcinoma in white female patients was one for the years 1961, 1963, 1976, 1982, and 1988 through 1990. The frequency of adenocarcinoma in black female patients was two in 1987 and one for the years 1989 and 1990. Although the numbers are small, there was an increase in the number of white and black female patients with adenocarcinoma after 1984.

The yearly number of patients with SCCA who underwent biopsy (nonsurgical therapy) versus resection (surgical therapy) is shown in Fig. 5. The number of patients with SCCA treated without resection equaled or exceeded the number of patients treated with resection for all recorded years. The total number of resections for patients with SCCA was 225. In two years, 1962 and 1993, the biopsy and resection rates were equal, and in both of these two years the number of resections was comparatively low. The shape of the two curves, from 1968 to the present, was approximately the same.

The yearly number of patients with adenocarcinoma who underwent biopsy (nonsurgical therapy) versus resection (surgical therapy) is shown in Fig. 6. The number of patients treated with and without resection was equal between 1959 and 1987. After 1987 , the number of patients undergoing resection exceeded the number of patients who underwent biopsy and were treated without operation. The total number of resections for patients with adenocarcinoma was 170 .

Between March 1989 and April 1994, 45 patients with locoregional esophageal cancer (SCCA 12 patients, adenocarcinoma 31 patients, undifferentiated 2 patients) were treated with preoperative chemoradiation followed by operation. These results have been previously reported. ${ }^{1}$

\section{Discussion}

Since 1987 we have observed a predominance of adenocarcinoma in patients undergoing esophageal resection for carcinoma at our institution. To discover whether this observation represented an actual change in the prevalence of esophageal adenocarcinoma or whether it was a result of surgical selection bias, the Johns Hopkins Hospital surgical pathology records were reviewed for the years 1959 through 1994 to identify all patients in whom the pathologic diagnosis of primary esophageal SCCA or adenocarcinoma was made to determine the yearly prevalence and number of resections in patients with esophageal SCCA and adenocarcinoma. The study design uses our institution as its own control, and interpretation of the data assumes, we believe reasonably, that there has been no major change in the referral patterns or indications for esophageal resection at our institution during the study period and that all patients in whom a diagnosis of esophageal SCCA or adenocarcinoma is 


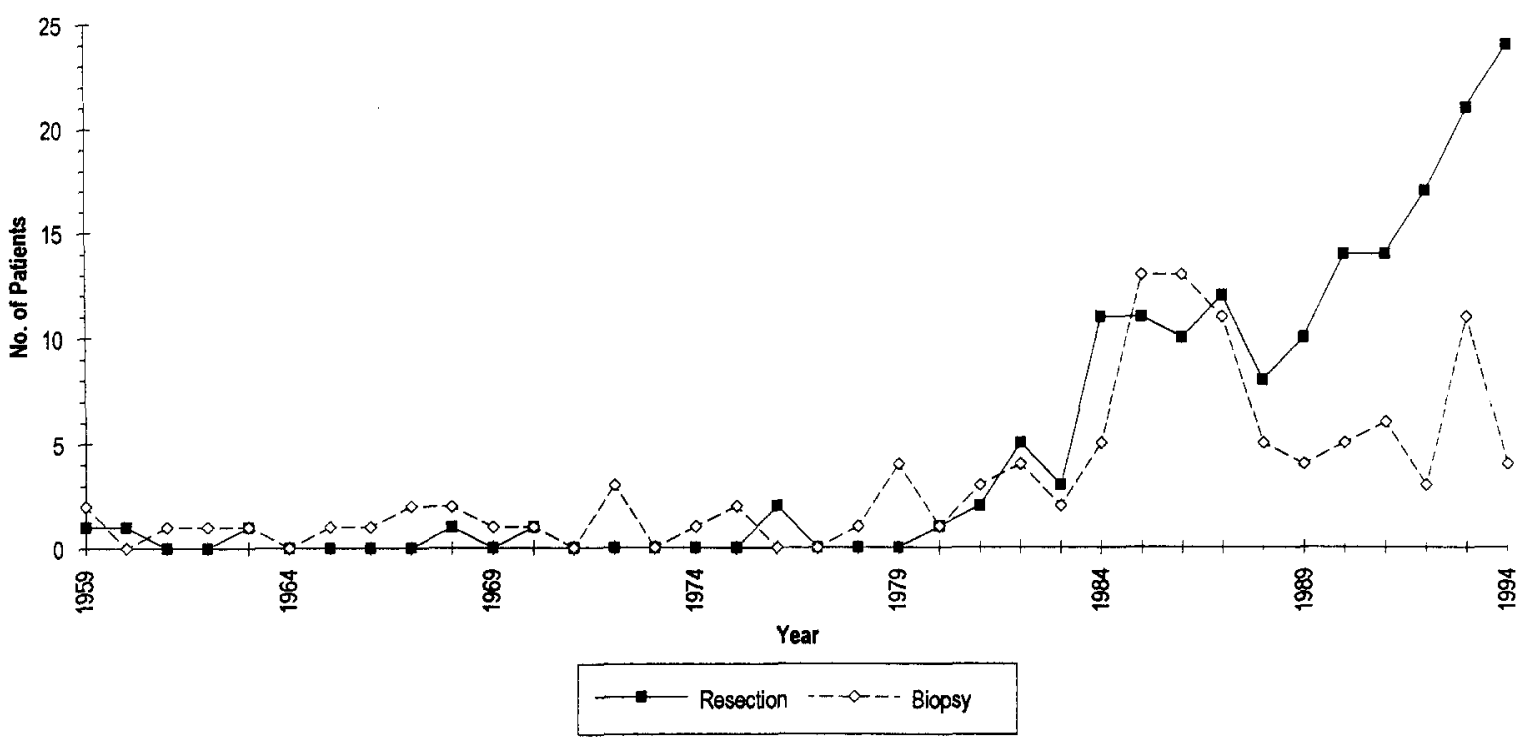

Fig. 6. Yearly number of total patients with adenocarcinoma treated with and without (biopsy) surgical resection.

made remain at our institution for subsequent therapy.

Overall, SCCA was the most common cell type, with 817 cases identified versus 284 cases of adenocarcinoma. However, the yearly prevalence and patient characteristics of esophageal SCCA and adenocarcinoma have not remained stable (Fig. 1). The number of patients with SCCA rose slowly from 1959 to 1992 , but since 1992 the number has been decreasing. Whereas adenocarcinoma was uncommon before 1978, its frequency has dramatically increased since that time and its frequency exceeded that of SCCA in 1994 for the first time since 1959. Adenocarcinoma is a disease almost exclusively of white men (Fig. 4), although interestingly the increase in the prevalence of adenocarcinoma is also demonstrated in black and white women.

The changes in the yearly frequency of esophageal SCCA and adenocarcinoma that we have noted appear to be representative of what is being observed nationally. National statistics from the Surveillance Epidemiology and End Results (SEER) database $^{2}$ show only a slight increase (from 3.0 to 3.5 per 100,000 ) in age-adjusted mortality rates for all patients with esophageal carcinoma from 1973 through 1991. On the other hand, the SEER data confirm that the distribution of esophageal SCCA and adenocarcinoma is changing. During the 4-year period 1978 to 1982 , the histologic distribution of esophageal cancer was SCCA 72\%, adenocarcinoma $13 \%$, and other $15 \%$. By 1988 to 1991, SCCA had fallen to $56.4 \%$, adenocarcinoma had increased to $28.4 \%$, and other esophageal cancers remained stable at $15.2 \%$. Other single-institution studies show similar trends. Yang and Davis ${ }^{3}$ demonstrated a 74\% increase between 1973 and 1982 in adenocarcinoma in white men and only a $30 \%$ increase in SCCA in black men and women. Pera and associates $^{4}$ reported that the incidence of adenocarcinoma in Olmsted County, Minnesota, rose significantly from 1974 to 1989 , during which time the incidence of SCCA fell. Blot and associates ${ }^{5}$ showed that the incidence of adenocarcinoma of the esophagus and gastric cardia rose between 1976 and 1987 at a rate that exceeded that of skin melanoma, nonHodgkin's lymphoma, and lung cancer, whereas the incidence of SCCA remained stable. An increase in esophageal adenocarcinoma has also been reported in the United Kingdom, ${ }^{6}$ Sweden, ${ }^{7}$ and Western Europe. $^{8}$

The observed variation in the number of patients with SCCA most likely reflects changing alcohol consumption and cigarette use, which are both documented causative agents for this disease. $\mathrm{Nu}$ merous risk factors for esophageal adenocarcinoma have been proposed, including tobacco use, ${ }^{9-13}$ alcohol consumption, ${ }^{9-11,13}$ dietary factors, ${ }^{13}$ genetic tendency, ${ }^{14,15}$ socioeconomic status, and peptic ul- 
cer disease. ${ }^{10}$ However, none of these factors is sufficient to explain the dramatic increase in esophageal adenocarcinoma noted since 1978. On the other hand, there is a documented association of Barrett's esophagus (BE) and esophageal adenocarcinoma. Exactly what aspect of gastroesophageal reflux or its therapy has led to an increase in $\mathrm{BE}$-associated adenocarcinoma, however, remains unclear. Two explanations that have been proposed are genetic alterations ${ }^{16,17}$ and the intriguing hypothesis that the increasing prevalence of adenocarcinoma may be iatrogenic in relation to the use of pharmaceutical agents that relax the lower esophageal sphincter. ${ }^{18}$ The reported prevalence of BE in patients who undergo esophagectomy for adenocarcinoma has remained stable. In two earlier reports from our institution, BE was found in $63 \%^{19}$ and $64 \%$ of patients with resected adenocarcinoma. These figures are identical to those of the Mayo Clinic experience reported by Pera and associates. ${ }^{4}$

The number of patients with SCCA treated without surgical resection exceeded the number of those who underwent resection by as much as $24: 1$, except during the years 1962 and 1993 (Fig. 6). No change in referral patterns or surgical treatment practice can be identified that would account for this observation. Cigarette smoking and alcohol consumption, related medical complications, and more advancedstaged tumors on presentation as a result of tumor location are possible explanations for the observed low resection rate in SCCA. From 1959 to 1992, the biopsy and resection rate curves generally remained parallel, suggesting that during that period there was little change in the treatment of patients with SCCA tumors. Since 1992, the ratio of nonoperative to operative therapy has approached 1:1.

The numbers of patients with adenocarcinoma treated with and without resection have been equivalent between 1959 and 1987. Since that time, the number of patients undergoing resection has exceeded that of patients treated nonoperatively. Tumor location (lower half of the esophagus), fewer medical complications related to smoking and drinking, and more favorable tumor staging because of the high proportion of patients with adenocarcinoma receiving medical care for reflux-related sequelae are possible reasons for the high resection rate in patients with adenocarcinoma. Another possible cause for the increased frequency of resections in patients with adenocarcinoma at our institution may have been our belief that BE with high-grade dysplasia is an indication for esophageal resection and reconstruction. Regardless of attempts to identify early-stage tumors, locally advanced-stage disease (American Joint Committee for Cancer stage III) continues to be the most common finding in patients undergoing resection for adenocarcinoma. ${ }^{20}$

The predominance of adenocarcinoma in patients undergoing esophageal resection for carcinoma, therefore, appears to result from two factors: an overall increase in the prevalence of adenocarcinoma since 1978 and an increased likelihood of resection in patients with these tumors.

\section{REFERENCES}

1. Forastiere AA, Heitmiller RF, Lee DJ, Abrams R, Zahurak $\mathrm{M}$. A 4-week intensive preoperative chemoradiation program for locoregional cancer of the esophagus (abstract). Proc Am Soc Clin Oncol 1994;13:195

2. Thomas RM, Sobin LH. Gastrointestinal cancer. Cancer 1995; 75:154-70.

3. Yang PC, Davis S. Incidence of cancer of the esophagus in the U.S. by histologic type. Cancer 1988;61:612-7.

4. Pera M, Cameron AJ, Trastek VF, Carpenter HA, Zinsmeister AR. Increasing incidence of adenocarcinoma of the esophagus and esophagogastric junction. Gastroenterology 1993;104:510-3.

5. Blot J, Devesa SS, Kneller RW, Fraumen JF. Increasing incidence of adenocarcinoma of the esophagus and gastric cardia. JAMA 1991;265:1287-9.

6. Powell J, McConkey CC. Increasing incidence of adenocarcinoma of the gastric cardia and adjacent sites. $\mathrm{Br} \mathrm{J}$ Cancer 1990;62:440-3.

7. Hansson LE, Sparen $P$, Nyren $O$. Increasing incidence of both major histologic types of esophageal carcinomas among men in Sweden. Int J Cancer 1993;54:402-7.

8. Reed PI. Changing pattern of oesophageal cancer. Lancet 1991;338:178.

9. Paraf F, Flejou JF, Pignon JP, Fekete F, Potet F. Surgical pathology of adenocarcinoma arising in Barrett's esophagus: analysis of 67 cases. Am J Surg Pathol 1995;19:183-91.

10. Brown LM, Silverman DT, Pottern LM, et al. Adenocarcinoma of the esophagus and esophagogastric junction in white men in the United States: alcohol, tobacco, and socioeconomic factors. Cancer Causes Control 1994;5:333-40.

11. Gao YT, McLaughlin JK, Blot WJ, et al. Risk factors for esophageal cancer in Shanghai, China: I-role of cigarette smoking and alcohol drinking. Int J Cancer 1994;58:192-6.

12. Menke-Pluymers MB, Hop WC, Dees J, van Blankenstein M, Tilanus HW. Risk factors for the development of an adenocarcinoma in columnar-lined (Barrett) esophagus (the Rotterdam Esophageal Tumor Study Group). Cancer 1993;72: $1155-8$.

13. Kabat GC, Ng SK, Wynder EL. Tobacco, alcohol intake, and diet in relation to adenocarcinoma of the esophagus and gastric cardia. Cancer Causes Control 1993;4:123-32.

14. Eng C, Spechler SJ, Ruben R, Li FP. Familial Barrett esophagus and adenocarcinoma of the gastroesophageal junction. Cancer Epidemiol Biomarkers Prev 1993;2:397-9.

15. Jochem VJ, Fuerst PA, Fromkes JJ. Familial Barrett's esoph- 
agus associated with adenocarcinoma. Gastroenterology 1992;102:1400-2.

16. Moore JH, Lesser EJ, Erdody DH, Natale RB, Orringer MB, Beer DG. Intestinal differentiation and p53 gene alterations in Barrett's esophagus and esophageal adenocarcinoma. Int J Cancer 1994;56:487-93.

17. Krishnadath KK, Tilanus HW, Alers JC, Mulder AH, van Dekken H. Detection of genetic changes in Barrett's adenocarcinoma and Barrett's esophagus by DNA in situ hybridization and immunohistochemistry. Cytometry 1994;15:17684.
18. Wang $\mathrm{HH}$, Hsieh CC, Antonioli DA. Rising incidence rate of esophageal adenocarcinoma and use of pharmacological agents that relax the lower esophageal sphincter (United States). Cancer Causes Control 1994;5:573-8.

19. Heitmiller RF. Esophageal tumors. In: Cameron JL, ed. Current surgical therapy. 5th ed. St. Louis, Missouri: MosbyYear Book, 1995:45-9.

20. Hamilton SR, Smith RR, Cameron JL. The prevalence and characteristics of Barrett esophagus in patients with adenocarcinoma of the esophagus and esophagogastric junction. Hum Pathol 1988;19:942-8.

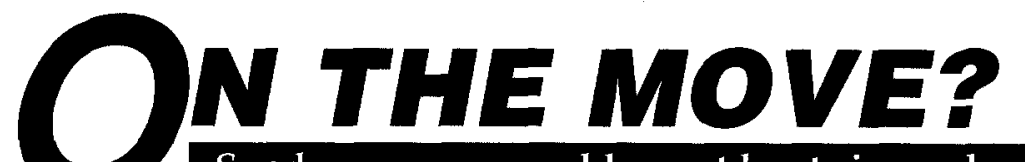

Send us your new address at least six weeks ahead

Don't miss a single issue of the journal! To ensure prompt service when you change your address, please photocopy and complete the form below.

Please send your change of address notification at least six weeks before your move to ensure continued service. We regret we cannot guarantee replacement of issues missed due to late notification.

JOURNAL TITLE:

Fill in the title of the journal here.

OLD ADDRESS:

Affix the address label from a recent issue of the journal here.

\section{NEW ADDRESS: \\ Clearly print your new address here.}

$\begin{array}{ll}\text { Name } & \\ \text { Address } \\ \text { City/State/ZIP } \\ \\ \\ \text { FAX TO: } & \text { OR PHONE: } \\ \text { 1-800-453-4351 } \\ & \text { Outside the U.S., call } \\ \text { 314-453-4351 }\end{array}$

Name

Address

City/State/ZIP

OR FAX TO:

$314-432-1158$

Journal Subscription Services

Mosby-Year Book, Inc.

11830 Westline Industrial Dr.

St. Louis, MO 63146-3318
1-800-453-4351

314-453-4351 